\title{
Lid changes in non-bullous ichthyosiform erythrodermia
}

H. M. ROSE

Liverpool

Ichthyosis is a condition in which the skin shows visible removable cutaneous scale $\vec{\omega}$ (Wells, i 966). It is due to a disturbance of the normal balance between formation anষ্ষ desquamation of skin keratin.

Ocular changes reported in ichthyosis are blepharitis, hypertrophic conjunctivitisi corneal vascularization, ectropion, lagophthalmos, and keratitis (Cordes and Hogani I939), corneal nodes (Vail, I940), and cataracts, optic atrophy, and retinitis pigmentos@ (Stewart, I939). Most writers have described single cases. Jay, Blach, and Wells ( $968 \AA$ analysed the ocular features of 62 cases, and found that lid and certain corneal changes were characteristic of the disease, while other changes were secondary or coincidental.

The disease was classified into four groups on genetic and clinical grounds by Well ( I 966).

The present paper reports three cases of the type called "congenital non-bullous igh thyosiform erythrodermia", which is characterized by the following features:

(a) autosomal recessive inheritance;

(b) presence at birth;

(c) congenital erythrodermia (which fades later);

(d) scaliness of the upper face, flexures, palms, and soles;

(e) worsening with age.

The patients were three siblings, two of whom showed, at the age of 2 weeks, ectropion of the upper lids with, in one eye, lagophthalmos without ectropion, caused by stiffness of the skin of the lids. There is no family history of ichthyosis, and the parents are nog consanguineous.

\section{Case reports}

(1) Tony (Date of birth February 10, 1970).

This baby was first seen by an ophthalmologist at the age of 2 weeks. At birth he had the appearanco of being encased in a tight red collodion membrane, which was the thickened horny layer of epidermis.? Fissures appeared in the skin surface, dividing it into peeling scaly areas in which the skin was dry firm, inelastic, paper-smooth, and brittle.

Fine fissures radiated from the outer canthi. There were no horizontal creases in the lids, pre? sumably because movements were impaired by stiffness; there were however some obliquely verticaf fine folds (along which the surface was cracked) in the upper lids, such as might result from upward traction in attempts at elevation. There was no blinking and no closure in sleep, and the lids 
remained half open at all times except with activity of the orbicularis in crying (Fig. I). The right upper lid was tented and its tarsal conjunctiva everted. When the right upper and lower lids were approximated, the margin of the upper rode in front of the lower. For the first 2 days after the eyes were examined, there was a small discharging abscess in the middle of the margin of the right upper lid. The associated swelling did cause closure of the lids, but when this had subsided, the right eye remained open again.

The left upper lid was not everted, but the left eye remained continuously open.

Only a few very fine short lashes were present. The puncta were normal.

The anterior segments of the globes were normal.

Conjunctival swabs grew staphyloccoci, sensitive to neomycin. Neomycin was instilled 4-hourly.

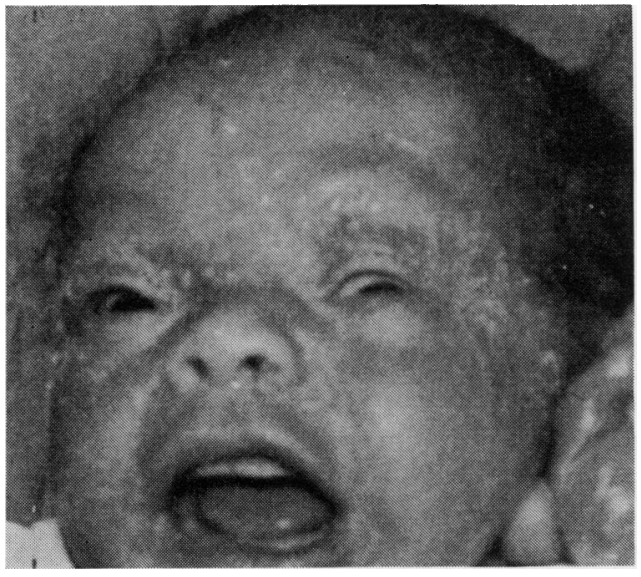

FIG. I Case I at 2 weeks. Eversion of right upper lid with exposure of conjunctiva

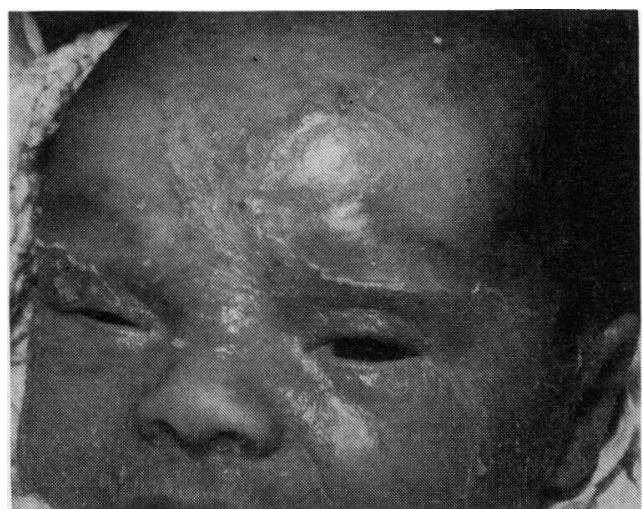

FIG. 2 Case I at 3 weeks. Over-riding of right lower lid by right upper lid

At this stage it was thought that the ectropion of the right upper lid was likely to increase and cause permanent exposure of the eye, with conjunctival and corneal changes. It was decided to do a tarsorrhaphy to correct the deformity and protect the globe.

After a further week, however, the lids appeared more active and there was some blinking to light, though with rather slow stiff motion and with only orbicularis action. The right upper lid was less everted and the tarsal conjunctiva was less exposed (Fig. 2). The cornea was clear. The eye still did not close fully except in crying. Operation was deferred.

A few days later (the baby being now one month old), the right upper lid was in normal apposition to the globe with no eversion. Lid movements were still better and the eyes closed in sleep. Under mydrilate, the media and fundi appeared to be normal.

During this period the condition of the skin generally improved: the original dry hard horny layer was shed in scales, revealing softer, more flexible, though still ichthyotic, skin underneath. From this time onwards the skin was treated with an ointment containing vitamin A acid, which has been recently used for various dyskeratotic skin conditions (Fulton, 1968).

\section{(2) Jacqueline (Date of birth August 21, 1967)}

This child had severe congenital ichthyosis. When seen at 16 days of age, she had ectropion of both upper lids, and a lateral tarsorrhaphy was done in the right eye and lateral and medial tarsorrhaphies in the left.

There was considerable infection, with an abscess in the left upper lid; all subsided with neobacrin ointment and chloramphenicol drops. 
Now, at the age of $2 \frac{1}{2}$ years, the lids have flexible skin with normal movements. There is residual $3 \mathrm{~mm}$. of lateral tarsorrhaphy in the left eye. There are a few matted lashed in the upper lids, and none in the lower.

This child shows severe mental ratardation as well as ichthyosis: she cannot walk or speak, and hæ a left hemiplegia with deformities of the left hand and foot. The eyes show course nystagmoid movements, and although she sometimes looks towards objects and follows a light, there is marked

lack of attention. The anterior segments, media, and fundi are normal.

(3) Joseph (Date of birth September 21, 1968).

This child has mild ichthyosis with normal lids and eyes, and in mentally normal.

\section{Comment}

Jay and others (1968) point out that the only type of ichthyosis in which ectropion occues is non-bullous ichthyosiform erythrodermia. In their cases and those of previous write (Hudson, I926; Cordes and Hogan, I939; Vail, 1940; Stewart, 1939), ectropion is de cribed as affecting the lower lids, and as developing secondarily to contracture.

The cases described here are of a different nature:

(I) The ectropion affected the upper lids, occurred neonatally, and was not progressive even resolving spontaneously in one case;

(2) One eye showed lagophthalmos without ectropion, because of stiffness of the skin the lid. In spite of some weeks non-closure, no corneal changes occurred.

The spasticity and mental retardation in the older child suggests comparison with the Sjøgren-Larsson syndrome (Wells, 1966) and the syndrome of Rud (Stewart, 1989to although there were no lens or retinal changes.

I should like to thank Dr. F. Hudson who referred the patients; and Mr. Alan Patterson for suggesting the this paper should be written.

\section{References}

Cordes, F. C., and hogan, M. J. (1939) Arch. Ophthal. (Chicago), 22, 590

Fulton, J. E. (1968) Arch. Derm., 98, 396

Hudson, A. c. (1926) Proc. roy. Soc. Med., 19, Sect. Ophthal., p. I I

JAY, B., BLACH, R. K., and Wells, R. s. (1968) Brit. F. Ophthal., 52, 217

STEWART, R. M. (1939) $\mathcal{F}$. Ment. Sci., 85, 256

VAIL, D. (1940) Arch. Ophthal. (Chicago), 24, 215

WELLS, R. s. (1966) Brit. med. F., 2, I504 